Article

\title{
Wheat Straw Biochar and NPK Fertilization Efficiency in Sandy Soil Reclamation
}

\author{
Magdalena Bednik *®D, Agnieszka Medyńska-Juraszek@ Michał Dudek, Szymon Kloc, \\ Agata Kręt, Beata Łabaz and Jarosław Waroszewski \\ Institute of Soil Sciences and Environmental Protection, Wroclaw University of Environmental and Life Sciences, \\ Grunwaldzka 53 St., 50-357 Wroclaw, Poland; agnieszka.medynska-juraszek@upwr.edu.pl (A.M.-J.); \\ michal.dudek@upwr.edu.pl (M.D.); szymonkloc1@gmail.com (S.K.); kret.agata.a@gmail.com (A.K.); \\ beata.labaz@upwr.edu.pl (B.Ł.); jaroslaw.waroszewski@upwr.edu.pl (J.W.) \\ * Correspondence: magdalena.bednik@upwr.edu.pl
}

Received: 25 February 2020; Accepted: 30 March 2020; Published: 1 April 2020

\begin{abstract}
Intensive land use including cultivation may result in soil degradation. Restoring natural conditions or utility values called reclamation usually requires prior improvement of soil properties by using fertilizers or soil amendments. Special attention is paid to biochar, as it can improve soil physical and chemical properties. Therefore, amendment is potentially useful for preparation of degraded soil for future vegetation. In pot experiments, we studied the effect of wheat straw biochar $(5 \% \mathrm{v} / \mathrm{w})($ soil with biochar $(\mathrm{S}+\mathrm{BC}))$, two rates of mineral fertilizer (no fertilizer as a control set (SC) and single initial dose of fertilizer (S + NPK)), and combination of biochar and fertilizer (S + B C + NPK) on sandy soil properties and grass growth. Biochar significantly increased soil $\mathrm{pH}$, total organic carbon content (TOC), and volumetric water content (VWC, $+24 \%$ after one week of measurements). However, dry mass of grass shoots was lower in S + BC than in SC (-38\%). It was also observed that, in fertilizer, applied sets high concentrations of salts caused crust formation, surface cracking, and overdrying. Considering the results, biochar may be useful for increasing sandy substrate fertility, providing proper conditions for revegetation during reclamation.
\end{abstract}

Keywords: biochar; NPK fertilizer; sandy soils; reclamation; soil health; soil quality

\section{Introduction}

Sandy soils are common worldwide, from temperate to semiarid and arid regions, estimated to cover 900 million ha. Despite cultivation, these soils are often infertile and their productivity depends on the organic carbon content and moisture conditions. Typical properties of sandy soils are low water-holding capacity, high permeability, and low ability to store or exchange nutrients [1]. Due to limited silt, clay, and organic matter contents, sandy soils have a weakly developed structure and are prone to degradation processes. Removing vegetation and topsoil layer, especially during opencast mining, decreases soil organic matter even more and intensifies water or nutrient retention problems, which are essential for plants growth [2]. Water and nutrient deficiency lead to changes in biological properties of sandy soils limiting plant and microbe development. Microbial activity in sandy soil is usually low [3], which can be observed as a priming effect on carbon and nitrogen turnover [4]. Soil microorganisms are very sensitive to environmental changes, and significant degradation of microbial community can occur following such disturbance, both in terms of total biomass and species composition [5]. This leads to a decision of land use change from cultivated to afforested and loss of agricultural areas globally. Sandy soil reclamation in terms of climate change and more severe drought periods might be challenging. There is an urgent need to develop new strategies of land protection and reclamation. One of common practices is using soil amendments in order to recreate the fertility 
of soil. Many different materials have been dedicated recently as soil amendments. Application of mineral fertilizers, which is recommended as a strategy to support plant growth, can be ineffective, causing risk of nitrogen leaching to waters or losses as gas into the atmosphere [6]. This brings the need to develop more complex remediation strategies improving soil properties, e.g., by increasing sorption capacity for nutrients and water, making mineral fertilization more efficient. Organic matter is important in the first stages of initial soil formation, especially at post-mining sites. Changes occurring in the initial soils related to their chemical composition, resources, the rate of organic matter, organic carbon and nitrogen accumulation, and the thickness of the humus horizons under the introduced plant communities may be important indicators of soil-forming processes and reclamation [7]. Different organic materials, e.g., sewage sludge, compost, peat, and poultry manure, have been used recently [8] as an amendment bringing good but usually short-term changes in soil properties. The main reason is quick mineralization of organic matter in dry soil and organic matter losses through leaching and volatilization. It is necessary to search for more stable forms of organic matter resistant to abiotic and biotic degradation for long-term effects of reclamation. Recently, a lot of attention has been paid to biochar as a very promising substrate for soil remediation. Several studies have demonstrated the effectiveness of some biochars to reduce metal toxicity in mine soils $[9,10]$. Sand- or rock-mining soils are in most cases not classified as toxic materials but as substrates with urgent need of basic property improvements like $\mathrm{pH}$, water retention, or nutrient storage capacity to increase chance for revegetation. Properties of biochar, such as high porosity which may improve water retention, ability to modify chemical properties, or long-term interaction with soil, make this amendment potentially useful in reclamation process. For example, Fellet et al. [11] described that, following incorporation of an orchard waste-derived biochar on lead and zinc mine tailing, the $\mathrm{pH}$, nutrient retention, cation exchange, and water-holding capacity increased significantly. Kelly et al. [12] suggested that biochar may be an effective strategy for reclamation of soils with water deficiencies like hard rock mine tailings. Unfortunately, the knowledge about biochar for reclamation purposes is still scarce and further research on this topic is necessary to verify efficiency of this material as an efficient soil amendment. Our study points out some knowledge gaps with direct questions, e.g., is biochar application alone enough to restore productivity of very poor sandy material? Or, should we merge biochar with mineral fertilizing to achieve better effects? The main aims of this study are therefore (i) to test biochar, mineral fertilization, and their combination on sandy substrate under conditions of pot experiment and (ii) to identify possible technical problems and usefulness of amendments regarding to a short-term application in sandy soil.

\section{Materials and Methods}

\subsection{Materials and Experimental Setup}

Sandy material (fine sand according to FAO (Food and Agriculture Organization of the United Nations) guidelines [13]) was collected from the top $25 \mathrm{~cm}$ layer of Nowogród Bobrzański sand and

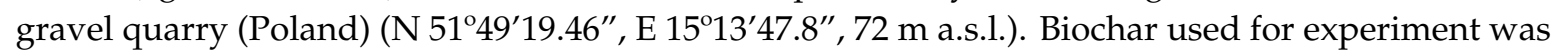
derived from wheat straw (Triticum L.) in Swidnica Industrial Equipment Factory, Poland. According to IBI (International Biochar Initiative) Standards, the product fulfills all the criteria required for its use as a soil amendment [14]. Biochar chemical properties were determined at Wroclaw University of Environmental and Life Sciences (WUELS). Sandy substrate samples for experimental purposes were analyzed in WUELS laboratories to determine standard properties.

For chemical characterization of wheat straw biochar, the $\mathrm{pH}$ (water) was measured in 1:5 (v/v) ratio with Mettller Toledo pH-meter. Elemental composition (CHN) was determined by elemental analyzer (CE Instruments Ltd., Hindley, UK). The ash content was determined by dry combustion in $550{ }^{\circ} \mathrm{C}$. The specific surface area (SSA) was obtained by N2-BET method using a TrisStar II 3020 (Micrometrics ${ }^{\circledR}$, Norcross, GA, USA) surface area analyzer [15]. Sandy substrate texture was measured by aerometric method, and $\mathrm{pH}$ and electrical conductivity (EC) potentiometrically (soil:water 1:5 v/v ratio) were measured on. $\mathrm{pH}$-meter and conductivity meter (Metller-Toledo, Greifensee, Switzerland). 
Cation exchange capacity was determined as a sum of base cations (MP-AES 4200, Agilent Technologies, Santa Clara, CA, USA, after extraction with ammonium acetate) and hydrolytic acidity (titration with $0.1 \mathrm{M} \mathrm{NaOH}$ potentiometrically, after extraction with $1 \mathrm{M}$ sodium acetate).

Biochar and sandy material properties are presented in Table 1.

Table 1. Characteristics of biochar and sandy substrate used in experiment.

\begin{tabular}{cc}
\hline Characteristic & Value \\
\hline \multicolumn{2}{c}{ Biochar } \\
\hline Substrate & wheat straw \\
Pyrolysis temperature & $550{ }^{\circ} \mathrm{C}$ \\
Pyrolysis time & $30 \mathrm{sec}$. \\
pH & 9.5 \\
Surface area & $230 \mathrm{~m}^{2} \mathrm{~g}^{-1}$ \\
Ash content & $30 \%$ \\
TOC & $65 \%$ \\
TN & $1.12 \%$ \\
\hline \multicolumn{2}{c}{} \\
Texture & Sandy substrate \\
pH (water) & loose sand $\left(93 \% \mathrm{sand}^{*} 6 \% \mathrm{silt}, 1 \%\right.$ clay) \\
EC & 6.99 \\
CEC & $2.60 \mu \mathrm{S} \mathrm{cm} \mathrm{cm}^{-1}$ \\
\hline
\end{tabular}

* TOC $=$ total organic carbon content, $\mathrm{TN}$ - total nitrogen content, $\mathrm{EC}=$ electrical conductivity, $\mathrm{CEC}=$ cation exchange capacity.

Following, experimental trials were set up in 2-L round plastic pots: control - only sand (SC), sand $+5 \%$ biochar ( $\mathrm{v} / \mathrm{w}$, equivalent to 42 tonnes per hectare) $(\mathrm{S}+\mathrm{BC}$ ), sand + NPK (nitrogen, phosphorus and potassium) mineral fertilizer( $\mathrm{S}+\mathrm{NPK})$, and sand $+5 \% \mathrm{BC}(\mathrm{v} / \mathrm{w}$, equivalent to 42 tonnes per hectare $)+\mathrm{NPK}(\mathrm{S}+\mathrm{BC}+\mathrm{NPK})$. Pot dimensions were as follows: approximately $17 \mathrm{~cm}$ diameter top $\times 13 \mathrm{~cm}$ diameter at the base $\times 13 \mathrm{~cm}$ depth. Applied mineral fertilizer was commercially available: YaraMila $^{\mathrm{TM}}$ Complex (YARA International ASA, Oslo, Norway) Biochar was mixed with the entire volume of airdried sandy substrate. Fertilizer was applied as an initial dose in the form of a water solution of the Yara Mila complex, as an equivalent to $75 \mathrm{~kg} \mathrm{~N} \mathrm{ha}^{-1}, 30 \mathrm{~kg} \mathrm{P} \mathrm{ha}^{-1}, 93 \mathrm{~kg} \mathrm{~K} \mathrm{ha}^{-1}$, and $50 \mathrm{~kg} \mathrm{~S} \mathrm{ha}^{-1}$-rates possibly close to recommended for sandy soils reclamation [7]. Solid form of the fertilizer was dissolved in distilled water $(5 \mathrm{mg}$ of fertilizer per $1 \mathrm{~L}$ of water); then, pots were watered only once with $100 \mathrm{~mL}$ of the solution, after germination of most seeds.

Turf mix consisting of species resistant to drought (Festuca rubra, Festuca arundinacea, Festuca trachyphylla, Lolium perenne, Trifolium repens, and Trifolium pretense) was sieved (75 grass and 5 seeds of legumes per pot). Each variant of the experiment was set up in 6 replicates. Pots were placed in a warm, shallow room and watered with distilled water as needed. Experiment was conducted for 11 weeks in summer months (June-August 2018).

\subsection{Water Content Measurements}

To determine impact of biochar addition on water content, during the experiment, the humidity of mixtures was measured daily for a period of 7 days with ProCheckGeomor Sensor (Geomor-Technik, Szczecin, Poland). Measurements were carried out in situ on substrates in pots with vegetation at the 8th week of experiment. Before humidity measurements, pots were adjusted with distilled water to the same content of water ( 0.26 of Volumetric Water Content, VWC). Measurements started from the next day; initially, $100 \mathrm{~mL}$ of water was added to each pot to keep $70 \%$ of the water-holding capacity. Soil water content corresponding to $100 \%$ field capacity was determined by weighing soil-filled pots after full watering. The weight corresponding to $70 \%$ field capacity was calculated, and the pots were watered to reach $70 \%$ field capacity ( $100 \mathrm{~mL}$ of water per pot per day). The quantity of $100 \mathrm{~mL}$ was 
estimated based on previous experiments of our lab team members. However, it was noticed that, during the first days, the moisture of soil mixture was constantly increasing in SC and S + BC set; therefore, water dose was reduced to $50 \mathrm{~mL}$ per pot in the next days to avoid plant damage.

\subsection{Chemical Analysis of the Mixture after Experiment}

In the material collected from pots after 11 weeks of incubation, standard chemical analyses were conducted. Substrate from pots was airdried; passed through a 2-mm sieve; homogenized; and stored in warm, dry place before being analyzed. Total organic carbon content was measured on CS-MAT 5500 analyzer (Ströhlein, Kaarst, Germany, currently Bruker AXS Inc., Madison, WI, USA), total nitrogen content was analysed by the Kjeldahl method using $\mathrm{N}$ analyser (Buchi Labortechnik GmbH, Essen, Germany), and $\mathrm{pH}$ in distilled water potentiometrically (soil: water 1:5 v/v ratio) was measured on pH-meter (Metller-Toledo, Greifensee, Switzerland). Sum of base cations was determined on MP-AES 4200 (Agilent Technologies, Santa Clara, CA, USA) after extraction with ammonium acetate at $\mathrm{pH}$ 7.02 [16], and hydrolytic acidity was measured by titration with $0.1 \mathrm{M} \mathrm{NaOH}$ potentiometrically after extraction with $1 \mathrm{M}$ sodium acetate. Cation exchange capacity was calculated as a sum of base cations and hydrolytic acidity [17].

\subsection{Plant Analysis}

During the experiment, grass shoots and legume biomass were harvested three times. Shoots were cut using steel scissors at the soil surface and then were weight to determine fresh biomass weight. Cut biomass was placed in paper bags; airdried in a warm, airy place; and then weighed to determine dry mass. Grass shoots were also measured in height from the soil surface to the end of the shoot using a plastic ruler.

\subsection{Statistical Analysis}

Substrate properties and plant growth parameters were analyzed statistically using Duncan test on the significance level $p=0.05$ with R v3.6.0 software (Agricolae package).

\section{Results}

Biochar and fertilizer had impact on many standard properties of sandy substrates. In treatments with biochar $(\mathrm{S}+\mathrm{BC}$ and $\mathrm{S}+\mathrm{BC}+\mathrm{NPK})$, it was noticed that soil $\mathrm{pH}$ increased significantly (letters indicating significant differences, Table 2 ) by $0.3-0.4$ units when compared to the control treatment. With fertilizer addition, soil $\mathrm{pH}$ increased only by 0.2 units compared to the control set (Table 2). Biochar application in combination with mineral fertilizer caused significant increase of total organic carbon content (TOC) from $0.12 \%$ in SC to even $0.45 \%$ TOC in S + BC + NPK soil. However, single biochar rates had less visible effects on TOC content than in combination with fertilizer $(0.27 \%$ TOC in $\mathrm{S}+\mathrm{BC}$ treatment vs $0.45 \%$ in S + BC + NPK) (Table 2). Total nitrogen content was the highest in S + BC + NPK treatment, but generally, nitrogen content was relatively low in each experimental set. Despite extremely low contents of $\mathrm{C}$ and $\mathrm{N}$ in the sandy material used as a substrate, biochar application changed the C:N ratio from 12:1 in SC to 14:1 in S + BC treatment. There was also positive biochar influence on cation exchange capacity (CEC) in soil. In S + BC treatment, CEC was $22 \%$ higher than in control. Combination of biochar with fertilizer leveled out the positive effect, as results of CEC in S + BC + NPK were comparable with SC and no significant differences were observed between treatments. NPK application caused significant decrease of CEC values in both $S+N P K$ and $S+B C+$ NPK treatments compared with the $\mathrm{S}+\mathrm{BC}$ variant (Table 2). 
Table 2. Effect of biochar and fertilizer on basic substrate properties: Letters indicate significant differences among the treatments $(p=0.05)$. SD values are given in brackets.

\begin{tabular}{cccccc}
\hline & $\mathbf{p H}$ & $\begin{array}{c}\text { TOC } \\
\mathbf{\%}\end{array}$ & $\begin{array}{c}\text { TN } \\
\mathbf{\%}\end{array}$ & $\begin{array}{c}\text { CEC } \\
\mathbf{c m o l}(+) \mathbf{k g}^{-\mathbf{1}}\end{array}$ & C:N \\
\hline SC & $7.04(0.08) \mathrm{c}$ & $0.12(0.04) \mathrm{c}$ & $0.008(0.004) \mathrm{cd}$ & $1.08(0.30) \mathrm{ab}$ & $12: 1$ \\
S + BC & $7.35(0.07) \mathrm{a}$ & $0.27(0.06) \mathrm{b}$ & $0.020(0.005) \mathrm{b}$ & $1.22(0.20) \mathrm{a}$ & $14: 1$ \\
S + NPK & $7.22(0.13) \mathrm{b}$ & $0.10(0.04) \mathrm{c}$ & $0.013(0.003) \mathrm{d}$ & $0.84(0.12) \mathrm{b}$ & $10: 1$ \\
S + BC + NPK & $7.33(0.07) \mathrm{ab}$ & $0.45(0.10) \mathrm{a}$ & $0.041(0.002) \mathrm{a}$ & $1.05(0.34) \mathrm{ab}$ & $11: 1$ \\
\hline
\end{tabular}

$\mathrm{TOC}=$ total organic carbon, $\mathrm{TN}=$ total nitrogen, $\mathrm{C}: \mathrm{N}=$ carbon to nitrogen ratio, SC - control set (only sand), S+BC sand with biochar, S+NPK - sand with mineral NPK fertilizer, S+BC+NPK - sand with biochar and fertilizer.

Biochar addition improved water retention of the sandy substrate. Lower humidity and higher water percolation were observed in SC and SC + NPK treatments, while biochar application caused increase of humidity in the $S+B C$ set. Fertilizer-applied sets $(S+N P K$ and $S+B C+N P K)$ showed susceptibility to overdrying, but in $S+B C+$ NPK set, water content was higher than in $S+N P K$ throughout the measurements (Figure 1).

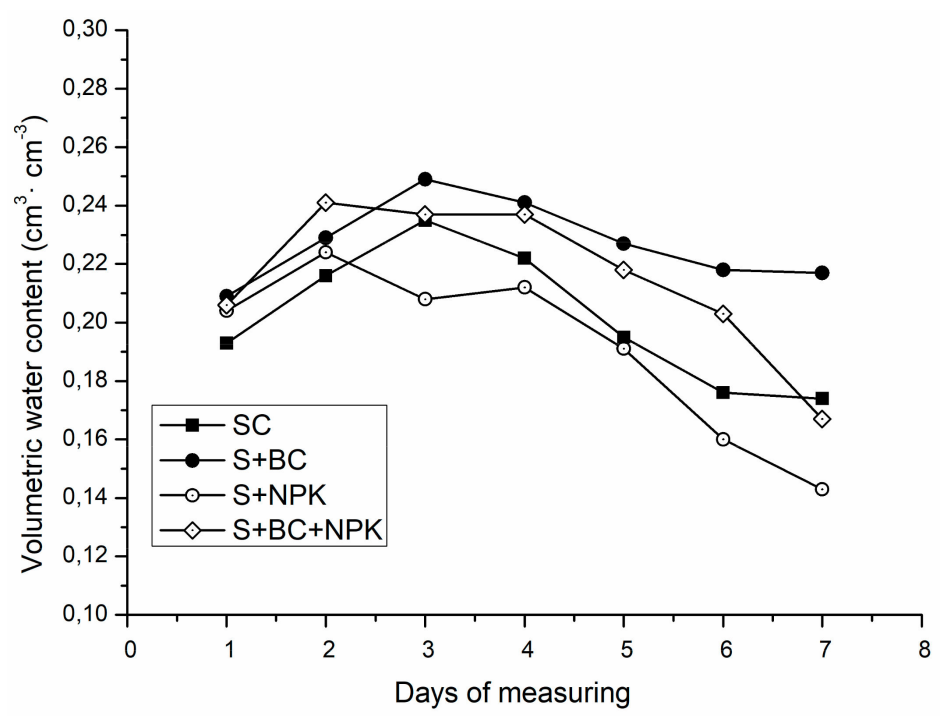

Figure 1. Effect of biochar and fertilizer on volumetric water content (VWC). SC- control set (only sand), S+BC - sand with biochar, S+NPK - sand with mineral NPK fertilizer, S+BC+NPK - sand with biochar and fertilizer.

Biochar and fertilizer application showed differential impact on plants biomass. Combination of both amendments increased grass and legume mix mean dry biomass by $+225 \%$ (dry mass of control: $0.61 \mathrm{~g}$ per pot). Application of fertilizer in S + NPK treatment gave a less noticeable positive effect, as dry biomass was only $44 \%$ higher when compared with control set. Biochar in turn decreased shoot dry biomass by $-38 \%$ (Figure 2). Results of fresh biomass weight confirm this tendency. In S + NPK + BC treatment, biomass after the third cut was $+244 \%$ higher than in the control set. Application of single mineral fertilizer in the S + NPK set increased fresh biomass by $+74 \%$ compared to control, while in $\mathrm{BC}$ treatment, biomass of shoots was $-58 \%$ lower than in not amended control treatment (Figure 2 ). 


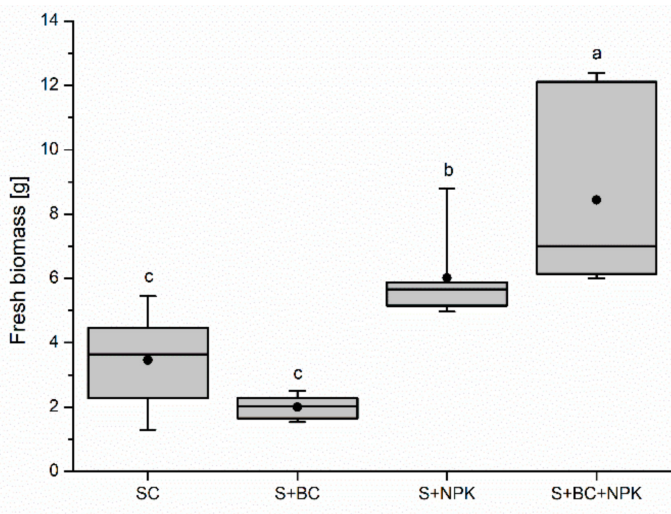

(a)

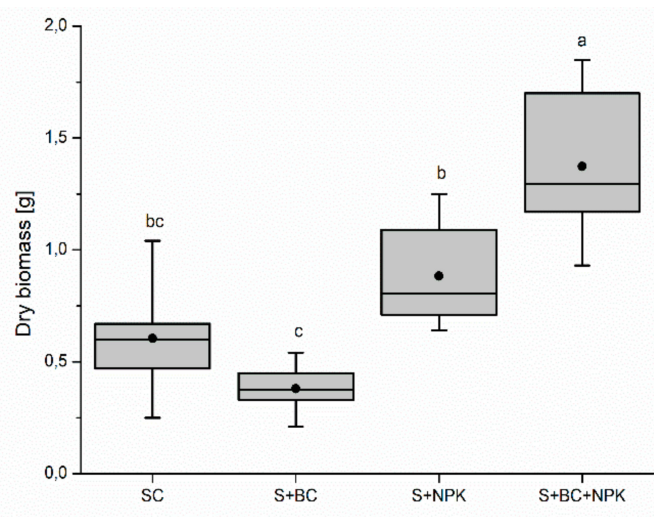

(b)

Figure 2. Effect of biochar and fertilizer on mean plants biomass (data from third cut): (a) fresh biomass and (b) dry biomass. Dots indicate mean values, horizontal lines in boxes indicate median. Letters indicate significant differences among the treatments $(p=0.05)$.

A similar negative effect of biochar on plant growth was indicated in plant height. The longest shoots were measured in S + BC + NPK treatment, while in the $\mathrm{S}+\mathrm{BC}$ set, plant growth was even weaker than in the control set (Figure 3).

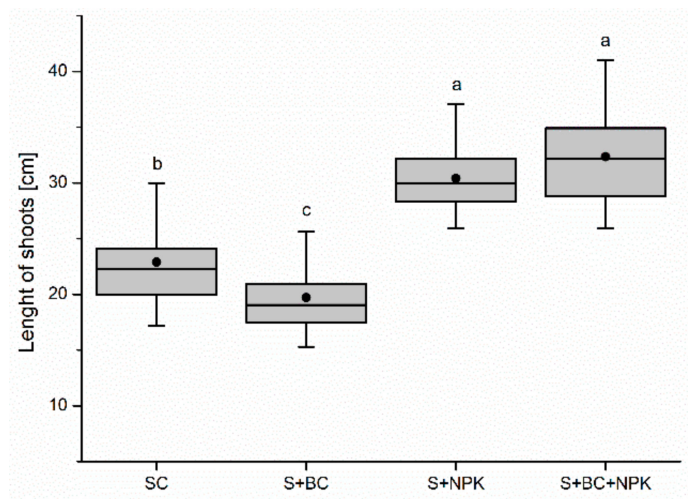

Figure 3. Effect of biochar and fertilizer on grass shoots length: Data from the last measurement (77th day of experiment). Dots indicate mean values, horizontal lines in boxes indicate median. Letters indicate significant differences among the treatments $(p=0.05)$.

\section{Discussion}

Our results have shown beneficial effect of biochar on some properties of sandy material, which may be useful during the reclamation process or improvement in sandy soil productivity. Liming effect of biochar application increasing soil $\mathrm{pH}$ is the most frequently discussed phenomena [18-21]. Similar findings were described by Novak et al. [22], who studied change of $\mathrm{pH}$ on loamy sand from the initial value 5.7 to 6.0 due to the application $2 \%$ of biochar, or by Chan et al. [23], who proved the ability of biochar to increase soil reaction on acid materials. High $\mathrm{pH}$ of biochar is an advantageous factor when applied to acidic soil. Biochar acts as a liming material, therefore, it can be used instead of calcium oxide [24]. Biochar, as an organic amendment, also has ability to increase TOC, which was proved in our study. Doubled TOC content in S + BC + NPK compared with S + BC treatment can be explained by higher input of biomass from the root system in NPK-fertilized sand. Similar findings were observed by Yost and Hartemink [1], indicating that mineral fertilization of sandy soil increases content of TOC. In the experiment, cation-exchange capacity has slightly increased after biochar application, while NPK caused decrease of CEC values, particularly visible in S + NPK treatment. Increase of CEC is usually observed on acidic soils [22], while under alkaline conditions, CEC changes are slightly visible 
or even CEC is decreased [15]. Decrease in CEC due to $\mathrm{Ca}^{2+}$ and $\mathrm{Mg}^{2+}$ declines were reported mostly in long-term experiments as a common problem after nitrogen fertilization [25]. Our results show that, also in short-term experiments, nitrogen fertilization may cause base cation imbalance in sorption complex. Another likely reason for low CEC value is leaching nutrients with water, as the pots were freely draining. However, authors had not investigated a nutrient balance between material in pots and leachates. Therefore, this statement is rather a supposition, but similar effect cannot be excluded under field conditions, where leaching is common problem.

In soils with very low $\mathrm{CEC}$, biochar can overtake the role of sorption complex and exchange cations with soil solution. The mechanism of changing CEC of soil-biochar mixtures was explained by Chintala et al. [26]. Biotic and abiotic factors during the incubation and slow oxidation of biochar in soil may cause modification of functional groups on their surface, which allows formation of organo-mineral complexes and finally enhances sorption capacity. However, it needs to be clearly stated that changes are more noticeable after long incubation time. In our study, the initial direction of changes was visible (CEC in S + BC and this variant was the highest), but relatively short incubation time seems not to be enough to observe them in a wider scope.

In sandy soils, nitrogen deficiency is a common problem. In tested sandy material from mining sites, total nitrogen was very low and increased after single BC application as well as when BC and NPK fertilization was applied simultaneously. Surprisingly, there was no significant increase of TN when single NPK application was tested. This can be explained by intensive uptake of nitrogen by grass, as NPK was applied only as a starting dose and not repeated. We assumed that, in NPK treatment, N losses were higher as biochar retained N in S + BC + NPK treatment. Biochar application brought the C:N ratio to value 14:1, considered typical for grasses in vegetative stage and providing proper conditions for microbial activity and nitrogen mineralization [27]. This is opposite to other studies showing that introduction of carbon-rich biochar may provide negative and wide C:N ratios [28], which cause significant soil $\mathrm{N}$ immobilization.

In loose sandy soils, water availability is the most important factor determining plant growth and nutrient availability from mineral fertilizers. Even in dry, hot seasons and in case of limited soil sorption capacity, most of the nutrients are lost due to intensive leaching during heavy rains of stormy origin or, regardless of the weather, by microbial activity [29]. Limited sorption capacity caused precipitation of the salts from soil solution, dryness, cracking, and quicker water runoff. Use of mineral fertilizers without increasing water retention and CEC by organic matter addition in sandy soils can lead to salt crust formation on soil surface inhibiting seed germination and plant growth. This phenomenon was observed at the first stage of pot experiment, which caused salt precipitation, crust formation, and problems with grass mix germination. However, this hypothesis needs further investigation under field conditions because salt crust formation is a common phenomenon in pot experiments due to limited soil volume, more regular watering, and higher air temperature under greenhouse conditions. Mechanisms of increasing soil water properties by the biochar was described by Karhu et al., [30] who pointed that there are two different possibilities: (1) high porosity of biochar and water absorption on particles surface and (2) creation and stabilization of soil structure by the organic amendment. Second property is particularly important on sandy soil, as biochar helps to create aggregate structure and mesopores in soil, which are conducive to keep water available for plants [31,32]. Authors claim that the best effects of biochar on water properties are observed for biochars produced in the temperature $550-600^{\circ} \mathrm{C}$, confirming high ability of used biochar to modify water retention. Based on our results, we suggest that biochar may have a positive impact on soil water availability, which is crucial for plants. A similar conclusion was made by Blackwell et al., who suggested that biochar seems to reduce drought stress, which can result in better crop growth and higher yields on drylands, especially in combination with intermediate rates of fertilizers [33].

Single biochar application had a negative impact on grass growth (biomass and shoots length), as availability of nitrogen is usually altered when biochar is applied to soil. Chan et al. [23] found that application of green waste biochar in the absence of nitrogen fertilizer had no positive effect on 
radish yield, even at the highest rate of $100 \mathrm{tha}^{-1}$. A number of studies have reported that adding biochar to soils may increase net nitrification rate [34], may stimulate $\mathrm{N}$ immobilization [35], may reduce $\mathrm{N}_{2} \mathrm{O}$ emission [36], may decrease $\mathrm{NH}_{3}$ volatilization, may enhance ammonium-oxidizing bacterial abundance [37], and may alter $\mathrm{N}$ availability for crops. Higher yield increases were observed with biochar application in the presence of $\mathrm{N}$ fertilizer, highlighting that biochar might play role in improving $\mathrm{N}$ use efficiency of crop plants [22]. Mechanisms underlying the $\mathrm{N}$ response to biochar additions are not well understood, but according to these reports, it is reasonable to hypothesize that biochar may retain $\mathrm{N}$ and, in theory, retard $\mathrm{N}$ leaching losses [34]. Our results prove that biochar is not a source of nitrogen for plant growth; however, when supporting soil sorption capacity, nitrogen fertilization in sandy soils is more efficient.

Biochar showed beneficial impact on numerous soil properties; however, its application alone is insufficient to restore productivity of infertile sandy material [38]. Despite the improvement of soil properties, biochar does not enhance grass growth or biomass production. These phenomena can be an obstacle in effective use of biochar as a soil amendment in agricultural areas, where high crop yields are crucial. Restoring soil productivity using only mineral fertilizers can also give negative effects, especially on sandy soils, as effectiveness of this method strongly depended on soil conditions, on applied dose, and on form of fertilizer. Water content and soil sorption capacity are the most important factors controlling nutrient release from fertilizer. Additionally, mineral fertilizers have no effect on soil properties, only supplying nutrients to the plant in the short-term periods. Biochar, in turn, did not act as a source of nutrients for plants but, as a material with high sorption capacity, could adsorb/precipitate even very limited amounts of nutrients or base cations from soil solution. It leads to the conclusion that simultaneous application of both amendments can create optimal conditions for biological reclamation of sandy soils. In the field practice, biochar can be mixed with soil by ploughing to depth of $25-30 \mathrm{~cm}$ to improve some soil properties, and vegetation can be stimulated by easily available nutrients delivered with fertilizers. The final effect will be creating stable habitat, suitable for plants introduced in reclamation process as well as for crops.

\section{Conclusions}

According to our studies, it was clearly indicated that biochar has a positive impact on soil water-holding capacity. Further research in the field condition is recommended, but based on our preliminary results of greenhouse experiment, it can be successfully applied to improve soil moisture of loose sandy material common in areas susceptible to overdrying, including reclaimed mining sites or cultivation areas. Biochar shows slight positive effect on some chemical properties of the soil (increasing $\mathrm{pH}$ and TOC), noticeable immediately after application. Contrary to reports from many authors, biochar did not clearly improve soil sorption properties (CEC), which may result from short incubation time. Due to the small plant growth in biochar-amended treatment, we recommend the addition of fertilizer at the initial dose to merge the positive effect of biochar and fertilizers, which guarantees effective biomass increase as well as improves a number of soil properties. Applying only mineral fertilizers is a one-way operation focused on high biomass production, but in this way, it is not possible to improve soil health. Biochar itself, in turn, depending on many factors may give less noticeable effects than expected and even inhibit plants growth, so prediction of its action in soil is difficult and need further investigations.

Author Contributions: Conceptualization, A.M.-J., B.Ł., and J.W.; formal analysis, M.B. and M.D.; funding acquisition, M.D.; investigation, M.B., A.M.-J., M.D., S.K., and A.K.; project administration, M.B.; resources, A.M.-J.; supervision, A.M.-J.; visualization, M.D.; writing-original draft, M.B. and M.D.; writing-review and editing, M.B., A.M.-J., M.D., S.K., A.K., B.Ł., and J.W. All authors have read and agreed to the published version of the manuscript.

Funding: This research was funded by The Quarry Life Award 2018, 4th edition, as a project being part of the research stream in the Polish national contest. Title of the project: "Biological reclamation of the Nowogród Bobrzański mining site as the way of increasing biodiversity". 
Acknowledgments: Authors are grateful to the management of Nowogród Bobrzański mining site for access to sampling area.

Conflicts of Interest: The authors declare no conflict of interest. The funders had no role in the design of the study; in the collection, analyses, or interpretation of data; in the writing of the manuscript; or in the decision to publish the results.

\section{References}

1. Yost, J.L.; Hartemink, A.E. Chapter Four - Soil organic carbon in sandy soils: A review. In Advances in Agronomy, 1st ed.; Sparks, D.L., Ed.; Academic Press: Newark, DE, USA, 2019; pp. 217-230.

2. Cummings, J.; Reid, N.; Davies, I.; Grant, C. Adaptive restoration of sand-mined areas for biological conservation. J. Appl. Ecol. 2005, 42, 160-170. [CrossRef]

3. Kautz, T.; Wirth, S.; Ellmer, F. Microbial activity in a sandy arable soil is governed by the fertilization regime. Eur. J. Soil Biol. 2004, 40, 87-94. [CrossRef]

4. Cely, P.; Tarquis, A.M.; Paz-Ferreiro, J.; Méndez, A.; Gascó, G. Factors driving the carbon mineralization priming effect in a sandy loam soil amended with different types of biochar. Solid Earth 2014, 5, 585-594. [CrossRef]

5. Mummey, D.L.; Stahl, P.D.; Buyer, J.S. Microbial biomarkers as an indicator of ecosystem recovery following surface mine reclamation. Appl. Soil Ecol. 2002, 21, 251-259. [CrossRef]

6. Kim, S.; Dale, B.E. Effects of nitrogen fertilizer application on greenhouse gas emissions and economics of corn production. Environ. Sci. Technol. 2008, 42, 28-33. [CrossRef]

7. Pietrzykowski, M.; Krzaklewski, W. Soil organic matter, $\mathrm{C}$ and N accumulation during natural succession and reclamation in an opencast sand quarry (southern Poland). Arch. Agron. Soil Sci. 2007, 53, 473-483. [CrossRef]

8. Larney, F.J.; Angers, D.A. The role of organic amendments in soil reclamation: A review. Can. J. Soil Sci. 2012. [CrossRef]

9. Beesley, L.; Moreno-Jiménez, E.; Gomez-Eyles, J.L.; Harris, E.; Robinson, B.; Sizmur, T. A review of biochars' potential role in the remediation, revegetation and restoration of contaminated soils. Environ. Pollut. 2011, 159, 3269-3282. [CrossRef] [PubMed]

10. Tang, J.; Zhu, W.; Kookana, R.; Katayama, A. Characteristics of biochar and its application in remediation of contaminated soil. J. Biosci. Bioeng. 2013, 116, 653-659. [CrossRef]

11. Fellet, G.; Marchiol, L.; Delle Vedove, G.; Peressotti, A. Application of biochar on mine tailings: Effects and perspectives for land reclamation. Chemosphere 2011, 83, 1262-1267. [CrossRef]

12. Kelly, C.N.; Peltz, C.D.; Stanton, M.; Rutherford, D.W.; Rostad, C.E. Biochar application to hardrock mine tailings: Soil quality, microbial activity, and toxic element sorption. Appl. Geochem. 2014, 43, 35-48. [CrossRef]

13. Jahn, R.; Blume, H.; Asio, V.; Spaargaren, O.; Schad, P. Guidelines for Soil Description, 4th ed.; Food and Agriculture Organization of the Uniterd Nations: Rome, Italy, 2006; pp. 25-30.

14. International Biochar Initiative. Available online: https://www.biochar-international.org/wp-content/ uploads/2018/04/IBI_Biochar_Standards_V2.1_Final.pdf (accessed on 21 February 2020).

15. Medyńska-Juraszek, A.; Ćwielag-Piasecka, I. Effect of Biochar Application on Heavy Metal Mobility in Soils Impacted by Copper Smelting Processes. Polish J. Environ. Stud. 2020, 29, 1749-1757. [CrossRef]

16. Gregorich, E.G.; Carter, M.R.; Angers, D.A.; Drury, C.F. Using a sequential density and particle-size fractionation to evaluate carbon and nitrogen storage in the profile of tilled and no-till soils in eastern Canada. Can. J. Soil Sci. 2009, 89, 255-267. [CrossRef]

17. Kabała, C.; Karczewska, A. Methods of soil and plant analysis. Available online: http://karnet.up.wroc.pl/ $\sim\{\}$ kabala/Analizy2017v8.pdf, (accessed on 5 February 2020).

18. Masud, M.M.; Li, J.Y.; Xu, R.K. Use of alkaline slag and crop residue biochars to promote base saturation and reduce acidity of an acidic ultisol. Pedosphere 2014, 24, 791-798. [CrossRef]

19. Windeatt, J.H.; Ross, A.B.; Williams, P.T.; Forster, P.M.; Nahil, M.A.; Singh, S. Characteristics of biochars from crop residues: Potential for carbon sequestration and soil amendment. J. Environ. Manag. 2014, 146, 189-197. [CrossRef]

20. Medyńska-Juraszek, A. Biochar as a soil amendment. Soil Sci. Annu. 2016, 67, 151-157. [CrossRef] 
21. Boersma, M.; Wrobel-Tobiszewska, A.; Murphy, L.; Eyles, A. Impact of biochar application on the productivity of a temperate vegetable cropping system. N. Zeal. J. Crop Hortic. Sci. 2017, 45, 277-288. [CrossRef]

22. Novak, J.M.; Busscher, W.J.; Laird, D.L.; Ahmedna, M.; Watts, D.W.; Niandou, M.A.S. Impact of biochar amendment on fertility of a southeastern coastal plain soil. Soil Sci. 2009, 174, 105-112. [CrossRef]

23. Chan, K.Y.; Van Zwieten, L.; Meszaros, I.; Downie, A.; Joseph, S. Agronomic values of greenwaste biochar as a soil amendment. Aust. J. Soil Res. 2007, 45, 629-634. [CrossRef]

24. Prasad, M.; Tzortzakis, N.; McDaniel, N. Chemical characterization of biochar and assessment of the nutrient dynamics by means of preliminary plant growth tests. J. Environ. Manag. 2018, 216, 89-95. [CrossRef]

25. Barak, P.; Jobe, B.O.; Krueger, A.R.; Peterson, L.A.; Laird, D.A. Effects of long-term soil acidification due to nitrogen fertilizer inputs in Wisconsin. Plant Soil 1997, 197, 61-69. [CrossRef]

26. Chintala, R.; Mollinedo, J.; Schumacher, T.E.; Malo, D.D.; Julson, J.L. Effect of biochar on chemical properties of acidic soil. Arch. Agron. Soil Sci. 2014, 60, 393-404. [CrossRef]

27. Brust, G.E. Chapter 9 - Management Strategies for Organic Vegetable Fertility. In Safety and Practice for Organic Food; Biswas, D., Micallef, S.A., Eds.; Academic Press: London, UK, 2019; pp. 193-212.

28. Šimanský, V.; Klimaj, A. How does biochar and biochar with nitrogen fertilization influence soil reaction? J. Ecol. Eng. 2017, 18, 50-54. [CrossRef]

29. Bohara, H.; Dodla, S.; Wang, J.J.; Darapuneni, M.; Acharya, B.S.; Magdi, S.; Pavuluri, K. Influence of poultry litter and biochar on soil water dynamics and nutrient leaching from a very fine sandy loam soil. Soil Tillage Res. 2019, 189, 44-51. [CrossRef]

30. Karhu, K.; Mattila, T.; Bergström, I.; Regina, K. Biochar addition to agricultural soil increased CH4 uptake and water holding capacity - Results from a short-term pilot field study. Agric. Ecosyst. Environ. 2011, 140, 309-313. [CrossRef]

31. Abel, S.; Peters, A.; Trinks, S.; Schonsky, H.; Facklam, M.; Wessolek, G. Impact of biochar and hydrochar addition on water retention and water repellency of sandy soil. Geoderma 2013, 202-203, 183-191. [CrossRef]

32. Ajayi, A.E.; Holthusen, D.; Horn, R. Changes in microstructural behaviour and hydraulic functions of biochar amended soils. Soil Tillage Res. 2016, 155, 166-175. [CrossRef]

33. Blackwell, P.; Krull, E.; Butler, G.; Herbert, A.; Solaiman, Z. Effect of banded biochar on dryland wheat production and fertiliser use in south-western Australia: An agronomic and economic perspective. Aust. J. Soil Res. 2010, 48, 531-545. [CrossRef]

34. Zheng, H.; Wang, Z.; Deng, X.; Herbert, S.; Xing, B. Impacts of adding biochar on nitrogen retention and bioavailability in agricultural soil. Geoderma 2013, 206, 32-39. [CrossRef]

35. Micks, P.; Aber, J.D.; Boone, R.D.; Davidson, E.A. Short-term soil respiration and nitrogen immobilization response to nitrogen applications in control and nitrogen-enriched temperate forests. For. Ecol. Manag. 2004, 196, 57-70. [CrossRef]

36. Spokas, K.A. Review of the stability of biochar in soils: Predictability of O:C molar ratios. Carbon Manag. 2010, 1, 289-303. [CrossRef]

37. Lehmann, J.; Rillig, M.C.; Thies, J.; Masiello, C.A.; Hockaday, W.C.; Crowley, D. Biochar effects on soil biota A review. Soil Biol. Biochem. 2011, 43, 1812-1836. [CrossRef]

38. Bista, P.; Ghimire, R.; Machado, S.; Pritchett, L. Biochar Effects on Soil Properties and Wheat Biomass vary with Fertility Management. Agronomy 2019, 9, 623. [CrossRef]

(C) 2020 by the authors. Licensee MDPI, Basel, Switzerland. This article is an open access article distributed under the terms and conditions of the Creative Commons Attribution (CC BY) license (http://creativecommons.org/licenses/by/4.0/). 